\title{
Role of pericytes in the retina
}

Eye (2018) 32, 483-486; doi:10.1038/eye.2017.220; published online 10 November 2017

Diabetic retinopathy is a major severe ocular complication associated with the metabolic disorder of diabetes mellitus. ${ }^{1}$ The lack of a detailed knowledge about the cellular and molecular mechanisms involved in diabetic retinopathy restricts the design of effective treatments. Understanding the roles of retinal cells during this process is of utmost importance, since gaining control of specific cell populations may allow us to arrest or even induce reversion of diabetic retinopathy.

Pericyte dropout or loss has been suggested to have great consequences on blood vessel remodeling, and possibly causes the first abnormalities of the diabetic eye which can be observed clinically in diabetic retinopathy. ${ }^{2}$ Nevertheless, a concreate evidence to support this concept is not available. Surprisingly, in a recent article in Nature Communications, Park and colleagues demonstrated that pericytes are not essential in the adult stable retinal blood vessels; and their selective depletion did not lead to a phenotype similar to diabetic retinopathy. ${ }^{3}$ The authors used a transgenic mouse model which can be used to specifically ablate PDGFR $\beta$ expressing pericytes (PDGFR $\beta$-CreER/DTA mice). Several studies suggest that PDGFB released from vascular endothelial cells recruits PDGFR $\beta$-expressing pericytes to facilitate vascular stabilization during blood vessel development. ${ }^{4}$ Nonetheless, whether this PDGFB/PDGFR $\beta$ signaling continues to be necessary for proper pericyte attachment to stable adult retinal vasculature was unknown. Park and colleagues used VE-Cadherin (Endothelial specific)-CreER/PDGFB floxed mice and intra-vitreal administration of PDGFR $\beta$ blocking antibody to show that PDGFB/ PDGFR $\beta$ signaling is not required for the maintenance of the interaction between pericytes and endothelial cells, and for the integrity of the blood-retinal-barrier in adults. ${ }^{3}$
In contrast, Park and colleagues demonstrated using state-of-the-art techniques, including deletion of several genes from endothelial cells, that PDGFB/PDGFR $\beta$ signaling is indispensable in the formation and maturation of bloodretinal-barrier at the postnatal stage through active recruitment of pericytes onto the growing retinal vessels. ${ }^{3}$ Additionally, the authors revealed that pericytes are important in the adult retina as regulators, as they control the expression of several genes (FOXO1, Ang2, and VEGFR2) to protect retinal vessels against injuries and stresses. ${ }^{3}$

Here, we discuss the findings from this work, and evaluate recent advances in our understanding of pericytes roles in the retina.

\section{Perspectives/future directions}

The findings from this study are based on the expression of PDGFR $\beta$ in pericytes. Several other pericytic markers have been characterized, such as nerve/glial antigen 2 (NG2) proteoglycan (CSPG4), ${ }^{5}$ aminopeptidase N (CD13), ${ }^{6}$ alpha smooth muscle actin ( $\alpha \mathrm{SMA}){ }^{7}$ ATP-sensitive potassium-channel Kir6.1, ${ }^{8}$ Glutamate aspartate transporter GLAST, ${ }^{9}$ desmin, ${ }^{9}$ leptin receptor, ${ }^{10}$ Nestin, ${ }^{11}$ and many others. ${ }^{12}$ However, there is no specific molecular marker that can be used to unmistakably identify pericytes. For instance, retinal microglia express NG2 and Nestin. ${ }^{13}$ Thus, it is possible that in the retina other cell populations are confused with pericytes. Additionally, pericytes that do not express NG2 proteoglycan were recently described. ${ }^{14}$ Currently, a state-of-the-art identification of pericytes in tissue preparations relies on a combination of anatomical localization (covering endothelial cells), morphology, and at least two pericytic molecular markers. Additionally, in adult mice, PDGFR $\beta$ expression is not restricted to pericytes. Several stromal cells, such as fibroblasts, ${ }^{15}$ and vascular smooth muscle cells ${ }^{16,17}$ express this cell-surface tyrosine kinase receptor. ${ }^{18}$ PDGFB plays an important role in the proliferation and differentiation of aortic and venous vascular smooth muscle cells. ${ }^{16,17}$ Also, 
not all cells in perivascular position are pericytes. In addition to pericytes, other cellular types have been described as perivascular: for instance, macrophages, 19 microglia, ${ }^{20}$ fibroblasts, ${ }^{21}$ adventitial cells, ${ }^{22}$ and vascular smooth muscle cells. ${ }^{23}$ Moreover, in earlier stages, PDGFR $\beta$ is broadly expressed throughout the animal in multiple cellular lineages. ${ }^{24}$ Thus, PDGFB/PDGFR $\beta$ signaling may occur between other cell populations as well, not necessarily pericytes. Altogether this highlights the possibility that some of the observations by Park et al. ${ }^{3}$ are due to a different, non-pericytic, cell population.

Curiously, Park and colleagues showed that after ablation of pericytes in the adult retina using PDGFR $\beta$ CreER/DTA mice, no changes in vascular leakage were detected in the retinas and brain, while profound leakage was found in several other peripheral organs. ${ }^{3}$ This may be due to the strong attachment between endothelial cells in the central nervous system in comparison with other parts of the body. ${ }^{25}$ These results also imply that the classical role of pericytes in vascular stability in adult blood vessels may be restricted to specific organs, but not others.

The population of pericytes has been uncovered to not be homogeneous whitin several organs. Interestingly, the functions of different pericyte subpopulations may vary. Specific pericyte subsets with distinct roles in myofiber regeneration, ${ }^{26}$ blood vessel formation, ${ }^{27}$ fat accumulation, $^{28}$ and fibrous tissue deposition ${ }^{29}$ in the skeletal muscle have been described. ${ }^{11}$ In the bone marrow and skin, $\mathrm{NG}^{+}$pericytes are distinct from NG2pericytes in their role for hematopoietic stem cells maintenance, ${ }^{30}$ and in their interaction with innate immune system cells, ${ }^{14}$ respectively. In several other organs, only a subpopulation of pericytes gives rise to myofibroblasts in organ-fibrosis. ${ }^{31}$ Whether PDGFR $\beta^{+}$ pericytes are heterogeneous in the retina remains unknown. As mentioned above, it is possible that PDGFR $\beta^{-}$pericytes may reside in the retina, and what is their function remains completely unknown.

In the mouse models that were analyzed in this study, the influence of PDGFB/PDGFR $\beta$ signaling from other tissues in the retina was neglected. Is it possible that the observations in the retinas of those transgenic mice come from an indirect effect from a phenomenon that occurred in another tissue? Future studies, using elegant techniques, including sophisticated whole-eye transplant experiments from transgenic mice into normal hosts, ${ }^{32}$ may address this issue. Thus, future studies should allow specific genetic interventions into the retina without affecting other tissues.

Interestingly, in a recent study, it was revealed that pericytes play a key role in the regulation of vascular tone and blood flow in the hypoxic spinal cord after injury. ${ }^{33}$ Strikingly, blocking pericytes-specific enzymes diminished hypoxia, and improved motor function and locomotion of the spinal cord-injured animals. ${ }^{33}$ As

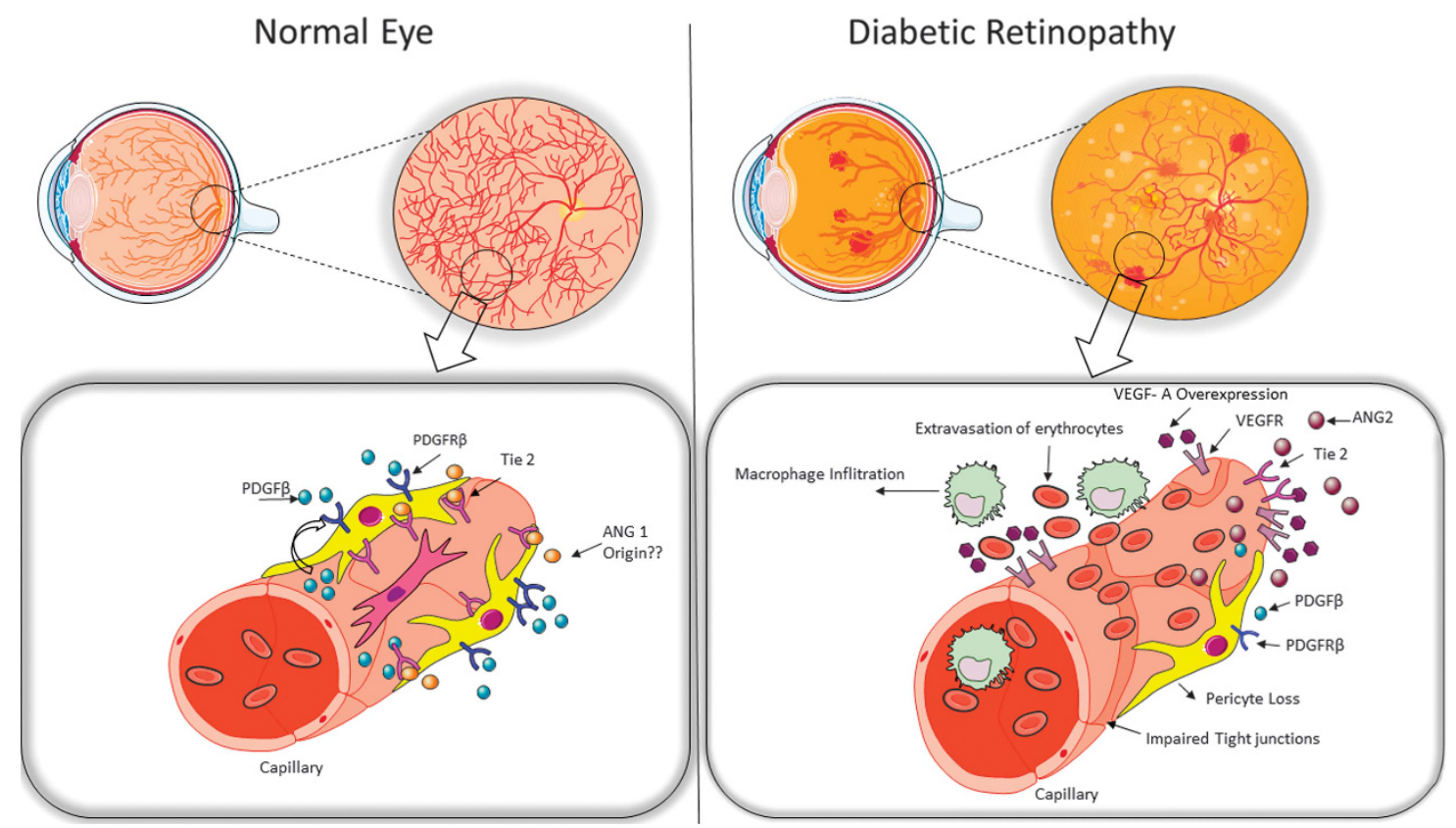

Figure 1 Retinal vasculature in diabetic retinopathy. Pericytes are present around blood vessels in the normal retina. Pericyte dropout is one of the major hallmarks of diabetic retinopathy. Park and colleagues now suggest that pericytes are essential in the formation and maturation of blood-retinal-barrier at the postnatal stage through active recruitment of pericytes onto the growing retinal vessels. ${ }^{3}$ Nevertheless, pericytes are not indispensable in the adult stable retinal blood vessels; and their selective depletion did not lead to a phenotype similar to diabetic retinopathy. Future studies may reveal other role of retinal pericytes in much greater detail. 
diabetic retinopathy can develop from ischemia-induced retinal hypoxia; ${ }^{34}$ hypothetically, blocking pericytes would ameliorate this ischemic condition if retinal pericyte have a similar role to medullar pericytes. Therefore, future studies should focus on investigating whether targeting retinal pericytes in a mouse model of diabetic retinopathy will alleviate hypoxia.

Cell-based therapies have been proposed as an option for both preventing neurovascular damage, and promoting regeneration of damaged cells in the retina in diabetic retinopathy. ${ }^{35}$ However, it is naive to think that injecting exogenous cells can work better than activating endogenous stem cells to work properly. The problem is that we do not know yet how exactly endogenous retinal cells work and how to regulate their functions.

Understanding the interplay between various cellular components of the retinal microenvironment, including endogenous stem cells, will be important to develop methods to regulate and activate endogenous stem cells in the retina. Pericytes role as stem cells contributing to formation of other cell types has been reported in numerous publications in several tissues. For instance, pericytes have neural progenitors' activity in response to ischenmia in vivo in the central nervous system. ${ }^{36}$ However, whether endogenous retinal pericytes have the plasticity to form other cellular populations remains unknown. If yes, why their efficiency is not enough to revert the disease state in diabetic retinopathy?

In conclusion, the study by Park and colleagues reveals important roles of pericytes during development and in the adult retina microenvironment. However, our understanding of the importance of pericytes in the retina remains limited, and the complexity of the retinal cellular microenvironment should be elucidated in future studies. The best is to come. A big challenge for the future will be to translate mice research into humans. Improving the availability of human tissue samples will be essential to reach this goal (Figure 1).

\section{Conflict of interest}

The authors declare no conflict of interest.

\section{Acknowledgements}

Alexander Birbrair is supported by a grant from Próreitoria de Pesquisa/Universidade Federal de Minas Gerais (PRPq/UFMG) (Edital 05/2016); Akiva Mintz is supported by the National Institute of Health (1R01CA179072-01A1) and by the American Cancer Society Mentored Research Scholar grant (124443MRSG-13-121-01-CDD).

\section{References}

1 Klein BE. Overview of epidemiologic studies of diabetic retinopathy. Ophthalmic Epidemiol 2007; 14(4): 179-183.

2 Beltramo E, Porta M. Pericyte loss in diabetic retinopathy: mechanisms and consequences. Curr Med Chem 2013; 20(26): 3218-3225.

3 Park DY, Lee J, Kim J, Kim K, Hong S, Han S et al. Plastic roles of pericytes in the blood-retinal barrier. Nat Commun 2017; 8: 15296

4 Sweeney MD, Ayyadurai S, Zlokovic BV. Pericytes of the neurovascular unit: key functions and signaling pathways. Nat Neurosci 2016; 19(6): 771-783.

5 Ozerdem U, Grako KA, Dahlin-Huppe K, Monosov E, Stallcup WB. NG2 proteoglycan is expressed exclusively by mural cells during vascular morphogenesis. Dev Dyn 2001; 222(2): 218-227.

6 Kunz J, Krause D, Kremer M, Dermietzel R. The 140-kDa protein of blood-brain barrier-associated pericytes is identical to aminopeptidase N. J Neurochem 1994; 62(6): 2375-2386.

7 Verbeek MM, Otte-Holler I, Wesseling P, Ruiter DJ, de Waal RM. Induction of alpha-smooth muscle actin expression in cultured human brain pericytes by transforming growth factor-beta 1. Am J Pathol 1994; 144(2): 372-382.

8 Bondjers C, He L, Takemoto M, Norlin J, Asker N, Hellstrom $\mathrm{M}$ et al. Microarray analysis of blood microvessels from PDGF-B and PDGF-Rbeta mutant mice identifies novel markers for brain pericytes. FASEB J 2006; 20(10): 1703-1705.

9 Goritz C, Dias DO, Tomilin N, Barbacid M, Shupliakov O, Frisen J. A pericyte origin of spinal cord scar tissue. Science 2011; 333(6039): 238-242.

10 Kunisaki Y, Bruns I, Scheiermann C, Ahmed J, Pinho S, Zhang D et al. Arteriolar niches maintain haematopoietic stem cell quiescence. Nature 2013; 502(7473): 637-643.

11 Birbrair A, Zhang T, Wang ZM, Messi ML, Enikolopov GN, Mintz A et al. Skeletal muscle pericyte subtypes differ in their differentiation potential. Stem Cell Res 2013; 10(1): 67-84.

12 Morikawa S, Baluk P, Kaidoh T, Haskell A, Jain RK, McDonald DM. Abnormalities in pericytes on blood vessels and endothelial sprouts in tumors. Am J Pathol 2002; 160(3): 985-1000.

13 Wohl SG, Schmeer CW, Friese T, Witte OW, Isenmann S. In situ dividing and phagocytosing retinal microglia express nestin, vimentin, and NG2 in vivo. PLoS ONE 2011; 6(8): e22408.

14 Stark K, Eckart A, Haidari S, Tirniceriu A, Lorenz M, von Bruhl ML et al. Capillary and arteriolar pericytes attract innate leukocytes exiting through venules and 'instruct' them with pattern-recognition and motility programs. Nat Immunol 2013; 14(1): 41-51.

15 Ohlund D, Handly-Santana A, Biffi G, Elyada E, Almeida AS, Ponz-Sarvise $M$ et al. Distinct populations of inflammatory fibroblasts and myofibroblasts in pancreatic cancer. J Exp Med 2017; 214(3): 579-596.

16 Lindahl P, Johansson BR, Leveen P, Betsholtz C. Pericyte loss and microaneurysm formation in PDGF-B-deficient mice. Science 1997; 277(5323): 242-245.

17 Winkler EA, Bell RD, Zlokovic BV. Pericyte-specific expression of PDGF beta receptor in mouse models with normal and deficient PDGF beta receptor signaling. $\mathrm{Mol}$ Neurodegener 2010; 5: 32. 
18 Armulik A, Genové G, Betsholtz C. Pericytes: developmental, physiological, and pathological perspectives, problems, and promises. Dev Cell 2011; 21(2): 193-215.

19 Bechmann I, Priller J, Kovac A, Bontert M, Wehner T, Klett FF et al. Immune surveillance of mouse brain perivascular spaces by blood-borne macrophages. Eur J Neurosci 2001; 14 (10): 1651-1658.

20 Guillemin GJ, Brew BJ. Microglia, macrophages, perivascular macrophages, and pericytes: a review of function and identification. J Leukoc Biol 2004; 75(3): 388-397.

21 Soderblom C, Luo X, Blumenthal E, Bray E, Lyapichev K, Ramos J et al. Perivascular fibroblasts form the fibrotic scar after contusive spinal cord injury. J Neurosci 2013; 33(34): 13882-13887.

22 Crisan M, Corselli M, Chen WC, Peault B. Perivascular cells for regenerative medicine. J Cell Mol Med 2012; 16(12): 2851-60.

23 Wanjare M, Kusuma S, Gerecht S. Perivascular cells in blood vessel regeneration. Biotechnol J 2013; 8(4): 434-447.

24 Guimaraes-Camboa N, Cattaneo P, Sun Y, Moore-Morris T, $\mathrm{Gu} Y$, Dalton ND et al. Pericytes of Multiple Organs Do Not Behave as Mesenchymal Stem Cells In Vivo. Cell Stem Cell 2017; 20(3): 345-359.e5

25 Coisne C, Engelhardt B. Tight junctions in brain barriers during central nervous system inflammation. Antioxid Redox Signal 2011; 15(5): 1285-1303.

26 Birbrair A, Zhang T, Wang ZM, Messi ML, Enikolopov GN, Mintz A et al. Role of pericytes in skeletal muscle regeneration and fat accumulation. Stem Cells Dev 2013; 22 (16): 2298-2314

27 Birbrair A, Zhang T, Wang ZM, Messi ML, Olson JD, Mintz A et al. Type-2 pericytes participate in normal and tumoral angiogenesis. Am J Physiol Cell Physiol 2014; 307(1): C25-38.

28 Birbrair A, Zhang T, Wang ZM, Messi ML, Mintz A, Delbono O. Pericytes: multitasking cells in the regeneration of injured, diseased, and aged skeletal muscle. Front Aging Neurosci 2014; 6: 245 .

29 Birbrair A, Zhang T, Wang ZM, Messi ML, Mintz A, Delbono O. Type-1 pericytes participate in fibrous tissue deposition in aged skeletal muscle. Am I Physiol Cell Physiol 2013; 305(11): C1098-1113.

30 Asada N, Kunisaki Y, Pierce H, Wang Z, Fernandez NF, Birbrair A et al. Differential cytokine contributions of perivascular haematopoietic stem cell niches. Nat Cell Biol 2017; 19(3): 214-223.

31 Birbrair A, Zhang T, Files DC, Mannava S, Smith T, Wang ZM et al. Type- 1 pericytes accumulate after tissue injury and produce collagen in an organ-dependent manner. Stem Cell Res Ther 2014; 5(6): 122.

32 Bourne D, Li Y, Komatsu C, Miller MR, Davidson EH, He L et al. Whole-eye transplantation: a look into the past and vision for the future. Eye 2017; 31(2): 179-184.

33 Li Y, Lucas-Osma AM, Black S, Bandet MV, Stephens MJ, Vavrek $\mathrm{R}$ et al. Pericytes impair capillary blood flow and motor function after chronic spinal cord injury. Nat Med 2017; 23(6): 733-741.

34 Wang X, Wang G, Wang Y. Intravitreous vascular endothelial growth factor and hypoxia-inducible factor 1a in patients with proliferative diabetic retinopathy. Am J Ophthalmol 2009; 148(6): 883-889.

35 Shaw LC, Neu MB, Grant MB. Cell-based therapies for diabetic retinopathy. Curr Diab Rep 2011; 11(4): 265-274.

36 Nakagomi T, Molnar Z, Nakano-Doi A, Taguchi A, Saino O, Kubo $\mathrm{S}$ et al. Ischemia-induced neural stem/progenitor cells in the pia mater following cortical infarction. Stem Cells Dev 2011; 20(12): 2037-2051.

GS P Santos ${ }^{1}$, PH DM Prazeres ${ }^{1}$, A Mintz $^{2}$ and A Birbrair ${ }^{1}$

${ }^{1}$ Department of Pathology, Federal University of Minas Gerais, Belo Horizonte, MG, Brazil ${ }^{2}$ Department of Radiology, Columbia University Medical Center, New York, NY, USA

Correspondence: Professor A Birbrair, Department of Pathology, Federal University of Minas Gerais, Belo Horizonte, 30150-348, Brazil Tel: 5531 983806886; E-mail: birbrair@icb.ufmg.br 